\title{
Accelerated care versus standard care among patients with hip fracture: the HIP ATTACK pilot trial
}

\author{
The Hip Fracture Accelerated Surgical Treatment and Care Track (HIP ATTACK) Investigators
}

Competing interests: Mohit Bhandari has received consultancy fees or grants from Smith \& Nephew, Stryker, Amgen, Zimmer, Moximed,

Bioventus, DePuy and Eli Lilly. Mark Crowther has received grants or personal fees from Octapharma and CSL Behring. John Eikelboom has received honoraria or grants from Boehringer Ingelheim, Bristol-Myers Squibb, Pfizer, Bayer and Daiichi Sankyo. P.J. Devereaux has received grants from Abbott Diagnostics, AstraZeneca, Bayer, Boehringer Ingelheim, Bristol-Myers Squibb, Covidien, Stryker and Roche Diagnostics, and has participated in an advisory board meeting for GlaxoSmithKline and an expert panel meeting for AstraZeneca. No other competing interests were declared.

This article has been peer reviewed.

Correspondence to: P.J. Devereaux, philipj@mcmaster.ca

CMAJ 2014. DOI:10.1503 /cmaj.130901

\section{ABSTRACT}

Background: A hip fracture causes bleeding, pain and immobility, and initiates inflammatory, hypercoagulable, catabolic and stress states. Accelerated surgery may improve outcomes by reducing the duration of these states and immobility. We undertook a pilot trial to determine the feasibility of a trial comparing accelerated care (i.e., rapid medical clearance and surgery) and standard care among patients with a hip fracture.

Methods: Patients aged 45 years or older who, during weekday, daytime working hours, received a diagnosis of a hip fracture requiring surgery were randomly assigned to receive accelerated or standard care. Our feasibility outcomes included the proportion of eligible patients randomly assigned, completeness of follow-up and timelines of accelerated surgery. The main clinical outcome, assessed by data collectors and adjudicators who were unaware of study group allocations, was a major perioperative complication (i.e., a composite of death, preoperative myocardial

A nnually in North America, $0.8 \%$ of women and $0.4 \%$ of men aged 65 years or older experience a hip fracture. ${ }^{1}$ Patients who sustain a hip fracture face a high risk of serious complications (i.e., cardiovascular, venous thrombotic, infectious and hemorrhagic) $)^{2,3}$ that can result in a prolonged hospital stay and death: 30-day mortality is $9 \%$ among men and 5\% among women. ${ }^{1}$ Among surviving patients who were community-dwelling before their fracture, $11 \%$ become bed-ridden and $16 \%$ are admitted to a long-term care facility. ${ }^{4}$

A hip fracture results in pain, bleeding and immobility. These factors initiate inflammatory, hypercoagulable, catabolic and stress states that can precipitate medical complications. ${ }^{5-11}$ Early surgery shortens the exposure to these harmful states and, therefore, may reduce morbidity and mortality. Furthermore, earlier surgery may shorten the period of immobility, which may improve functional outcomes and reduce costs.

A meta-analysis of observational studies eval- infarction, myocardial injury after noncardiac surgery, pulmonary embolism, pneumonia, stroke, and life-threatening or major bleeding) within 30 days of randomization.

Results: Of patients eligible for inclusion, $80 \%$ consented and were randomly assigned to groups (30 to accelerated care and 30 to standard care) at 2 centres in Canada and 1 centre in India. All patients completed 30-day follow-up. The median time from diagnosis to surgery was 6.0 hours in the accelerated care group and 24.2 hours in the standard care group $(p<0.001)$. A major perioperative complication occurred in 9 $(30 \%)$ of the patients in the accelerated care group and $14(47 \%)$ of the patients in the standard care group (hazard ratio $0.60,95 \%$ confidence interval 0.26-1.39).

Interpretation: These results show the feasibility of a trial comparing accelerated and standard care among patients with hip fracture and support a definitive trial. Trial registration: ClinicalTrials.gov, no. NCT01344343. uating the timing of surgery for a hip fracture included 5 studies (involving 4208 patients and 721 deaths) that reported the adjusted risk of mortality. ${ }^{12}$ Earlier surgery, irrespective of the cut-off for delay ( 24,48 or $72 \mathrm{~h}$ ), was associated with significantly lower mortality (adjusted relative risk $0.81,95 \%$ confidence interval $[\mathrm{CI}]$ $0.68-0.96, p=0.01)$. Although these data are encouraging, the apparent benefit may be a result of residual confounding (e.g., sicker patients may have had surgery delayed for medical optimization, which may not have been adequately adjusted for in the analyses). Conversely, the real potential of early surgery may be underestimated because the greatest impact may occur when a hip fracture is treated much more quickly than the timelines assessed in the observational studies $(24,48$ or $72 \mathrm{~h}$ ), similar to how treatment of an acute myocardial infarction or stroke within hours has the most dramatic impact. ${ }^{13,14}$

In many countries, including Canada, most patients with a hip fracture wait longer than 
24 hours to undergo surgery. The 2 main reasons for delay are preoperative medical clearance and operating room access, ${ }^{15-21}$ both of which are potentially modifiable. We undertook a pilot trial to determine the feasibility (as assessed by the proportion of eligible patients randomly assigned, completeness of follow-up and timeliness of accelerated surgery) of a large randomized controlled trial (RCT) comparing accelerated care and standard care among adults with a hip fracture.

\section{Methods}

\section{Design and randomization}

Our pilot trial was a multicentre RCT that compared accelerated and standard care among adults with a hip fracture. The 3 participating centres (Hamilton Health Sciences and St. Joseph's Healthcare Hamilton in Hamilton, Ontario, and Sancheti Institute for Orthopaedics and Rehabilitation in Pune, India) are tertiary care hospitals. Before the trial, these centres each had a mean rate of admission for a hip fracture of 12 to 15 admissions per month. Although it was not possible to blind patients or health care providers, data collectors and outcome adjudicators were unaware of study group allocations.
Written informed consent was obtained before randomization. If a patient was unable to provide consent (e.g., because of dementia) consent was obtained from a substitute legal decision-maker. Research personnel randomly assigned patients using an interactive, Webbased randomization system maintained by the coordinating centre at the Population Health Research Institute in Hamilton, Ontario. We stratified patients by centre and by the type of planned surgery (open reduction and internal fixation, or arthroplasty). We applied block randomization within strata with randomly varied block sizes. Study personnel and investigators were unaware of block sizes.

The research ethics board at each site approved the trial (the first approving ethics board was the Hamilton Health Sciences Research Ethics Board).

\section{Patients and interventions}

Patients aged 45 years or older who, during weekday, daytime working hours, received a diagnosis of a hip fracture requiring surgical repair were potentially eligible for inclusion. We chose this time restriction to enhance the potential for rapid medical clearance and operating room access for patients assigned to accelerated

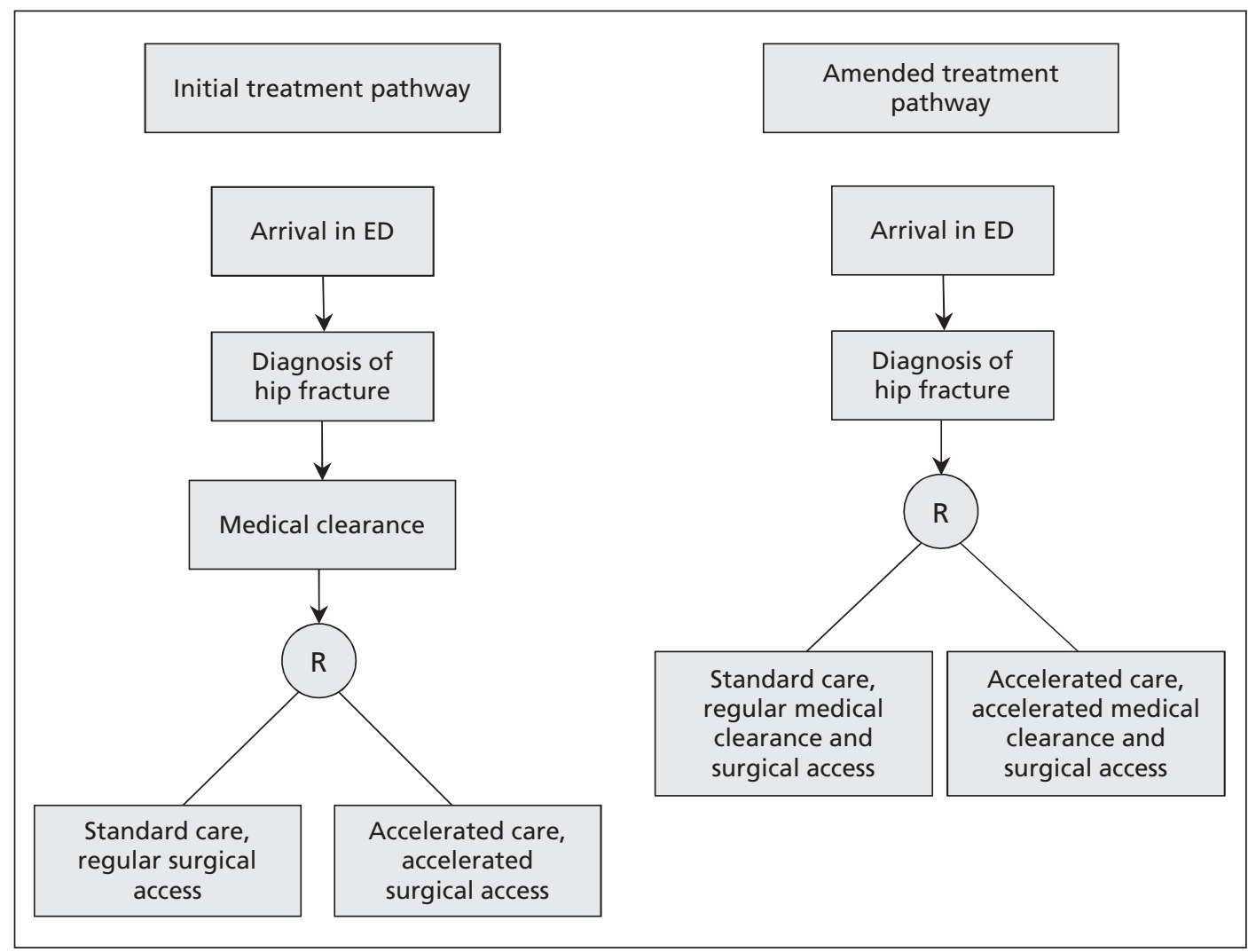

Figure 1: Initial and amended treatment pathways. The protocol was amended to randomly assign patients immediately on diagnosis so that only those assigned to early surgery received expedited medical clearance. $E D$ = emergency department. 
care. We modelled this strategy on the approach undertaken with percutaneous coronary intervention (PCI) among patients with acute ST elevation myocardial infarction (i.e., PCI was first established as effective during daytime working hours and then subsequently established after hours). ${ }^{22}$ We excluded patients who required emergent surgery (e.g., subdural hematoma), had an open hip fracture or were previously enrolled in the trial.

Initially, a trial specialist attempted to obtain medical clearance within 2 hours of the diagnosis. Once medical clearance was achieved, the study personnel assessed eligibility for inclusion in the study, obtained consent, and randomly assigned the patient to accelerated or standard care. After randomly assigning 11 patients (5 to standard care), we recognized that patients assigned to standard care were receiving early surgery because, having achieved accelerated medical clearance, they were put on the operating room list. We therefore amended the protocol to randomly assign patients immediately on diagnosis; only those assigned to early surgery received an expedited medical assessment (Figure 1).

Before starting the pilot trial, we achieved a consensus (through discussion with specialists in anesthesiology, cardiology, emergency medicine, thrombosis, infectious diseases, internal medicine, nephrology, neurology and orthopedics) that although patients with active comorbidities have an increased risk of perioperative adverse

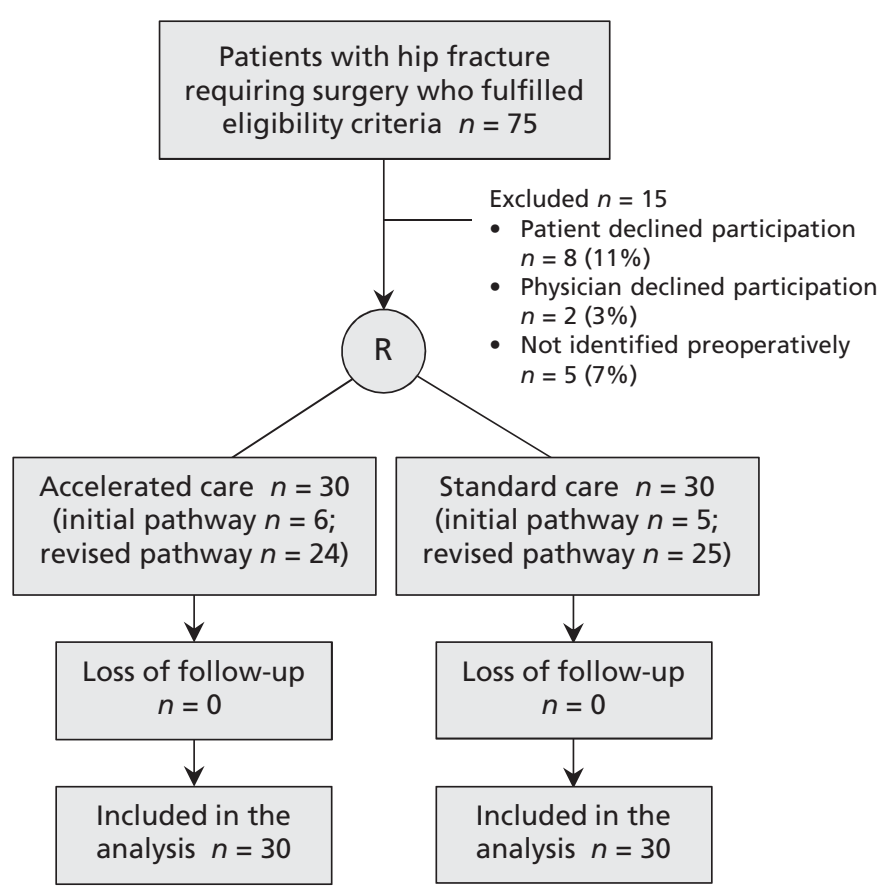

Figure 2: Flow of patients through the trial. events, ${ }^{23}$ only a minority of conditions are likely amenable to better outcomes by surgical delay, given the ensuing protracted exposure to the adverse states associated with a hip fracture. Appendix 1 (available at www.cmaj.ca/lookup /suppl/doi:10.1503/cmaj.130901/-/DC1) lists the conditions that the group believed would benefit from medical optimization before surgery, and which trial specialists considered when assessing the patient. Ultimately, each patient's situation was individually considered; the medical specialist, anesthesiologist and surgeon could delay the treatment of a patient assigned to accelerated surgery if they believed that the patient would benefit from medical treatment before surgery. Therefore, our change in protocol to randomly assign patients before medical clearance incurred some risk of randomly assigning patients to the accelerated care group who would not be rapidly cleared for accelerated surgery.

Soon after the trial started, some irreversible anticoagulants received regulatory approval. Two patients who had been randomly assigned (1 in each group) required substantial delays in surgery because of these agents. We subsequently excluded patients taking an irreversible therapeutic-dose anticoagulant. Patients randomly assigned to accelerated care who were taking warfarin were given prothrombin complex concentrate (PCC) to achieve an international normalized ratio (INR) of 1.5 or less (i.e., we administered PCC $20 \mathrm{IU} / \mathrm{kg}$ in the presence of an INR of $2-3$, PCC $30 \mathrm{IU} / \mathrm{kg}$ in the presence of an INR of 3-6, and PCC $40 \mathrm{IU} / \mathrm{kg}$ in the presence of an INR > 6).

Among patients randomly assigned to accelerated care, our process to obtain accelerated surgery (i.e., goal of surgery within $6 \mathrm{~h}$ of diagnosis) after obtaining medical clearance was to use the next orthopedic elective operating room slot (i.e., the patients were given priority over scheduled elective surgeries). Immediately after medical clearance was obtained, research personnel informed relevant individuals (e.g., the surgical booking clerk). When a patient assigned to accelerated surgery was given priority over a scheduled elective surgery, all the scheduled elective surgeries shifted a slot later in the day and were completed a few hours later than originally planned. The final scheduled elective surgery might then have occurred after normal working hours. To ensure that no elective surgery was cancelled, we covered the cost for each surgery that occurred after hours as a result of having accommodated a trial patient earlier in the day. To avoid cancellation of an elective surgery, centres randomly assigned only 1 patient each day (hospital administrators believed that the operating room 
could accommodate only 1 extra surgery after hours per day). Patients allocated to standard care were placed on the wait list for surgery according to local standard practices. Patients underwent either internal fixation or arthroplasty, at the surgeon's discretion.

\section{Follow-up and data collection}

On a daily basis, research personnel reviewed the medical records of admitted patients and documented trial outcomes. Patients underwent a daily troponin measurement on days 1 to 7 after randomization. Delirium was assessed daily on days 1 to 7 after randomization using the Confusion Assessment Method. ${ }^{24,25}$ Patients were followed until 30 days after randomization, and the final follow-up occurred in person or by telephone if the patient was discharged. If patients reported a potential study outcome, study personnel obtained corroborating evidence (e.g., source documents from a hospital chart).

We administered the Functional Independence Measure (FIM) ${ }^{26}$ motor domain and its mobility and locomotion subscales, and the 36Item Short Form Health Survey (SF-36) ${ }^{27-29}$ at 30 days. The motor domain of the FIM consists of 13 items, each scored on a scale of 1 to $7 .{ }^{26}$ The motor domain scores therefore range from 13 to 91, with high scores indicating superior function. The SF-36 measures health-related quality of life by scoring 8 domains (e.g., physical function, mental health). High scores indicate good quality of life. Phone administration of the FIM and SF36 has been validated in patients who underwent major hip surgery. ${ }^{30,31}$

Data entry occurred through iDataFax, a secure Internet-based data collection system with automated consistency and range checks. Additional approaches to ensure data quality included training of the research personnel and data integrity assessments by data management assistants.

\section{Outcomes}

The feasibility outcomes included successful random allocation of 60 patients during an 18-month period, the proportion of eligible patients randomly assigned (target $\geq 70 \%$ ) and the proportion of randomly assigned patients who completed 30-day follow-up (target $\geq 95 \%$ ). Among patients randomly assigned to accelerated care, we also evaluated the proportion who received medical clearance within 2 hours and initiation of surgery within 6 hours of the diagnosis of hip fracture.

Our main clinical outcome was a major perioperative complication (i.e., a composite of death, preoperative myocardial infarction, myocardial injury after noncardiac surgery, ${ }^{32}$ pulmonary embolism, pneumonia, stroke, and life- threatening or major bleeding) within 30 days of randomization. Trained outcome adjudicators who were unaware of treatment allocation evalu-

Table 1: Patient demographic and medical, surgical and anesthetic characteristics, by treatment group

\begin{tabular}{|c|c|c|}
\hline \multirow[b]{2}{*}{ Characteristic } & \multicolumn{2}{|c|}{ No. (\%) of patients* } \\
\hline & $\begin{array}{l}\text { Accelerated care } \\
\qquad n=30^{*}\end{array}$ & $\begin{array}{l}\text { Standard care } \\
\qquad n=30\end{array}$ \\
\hline Age, yr, mean \pm SD & $80 \pm 10$ & $83 \pm 9$ \\
\hline Female sex & $17(57)$ & $21(70)$ \\
\hline History of stroke & $8(27)$ & $3(10)$ \\
\hline History of TIA & 0 & $2(7)$ \\
\hline History of CAD & $5(17)$ & $7(23)$ \\
\hline History of coronary revascularization & $3(10)$ & $1(3)$ \\
\hline Moderate to severe aortic stenosis & 0 & 1 (3) \\
\hline History of PAD & $2(7)$ & 1 (3) \\
\hline History of atrial fibrillation & $5(17)$ & $7(23)$ \\
\hline History of CHF & $2(7)$ & 1 (3) \\
\hline CHF in hospital before randomization & 0 & 1 (3) \\
\hline History of DVT & $1 \quad(3)$ & $4(13)$ \\
\hline $\begin{array}{l}\text { Troponin T elevation in hospital } \\
\text { before randomization }\end{array}$ & 1 (3) & $3(10)$ \\
\hline History of hypertension & $20(67)$ & $21(70)$ \\
\hline History of diabetes & $3(10)$ & $1(3)$ \\
\hline History of COPD & $3(10)$ & $3(10)$ \\
\hline UTI in hospital before randomization & 0 & $1(3)$ \\
\hline eGFR $<30 \mathrm{~mL} / \mathrm{min}$ & $4(13)$ & $3(10)$ \\
\hline History of dementia & $6(20)$ & $4(13)$ \\
\hline Assistance with ADL before fracture & $8(27)$ & $10(33)$ \\
\hline Walking aid before fracture & $14(47)$ & $15(50)$ \\
\hline $\begin{array}{l}\text { Residence in a nursing home before } \\
\text { fracture }\end{array}$ & $6(20)$ & $6(20)$ \\
\hline $\begin{array}{l}\text { Time from fracture to ED, } h \text {, median } \\
\text { (Q1-Q3) }\end{array}$ & $1.9(1.2-6.2)$ & $1.6(1.1-3.5)$ \\
\hline $\begin{array}{l}\text { Time from arrival to diagnosis, } \mathrm{h} \text {, } \\
\text { median (Q1-Q3) }\end{array}$ & $2.9(2.4-5.3)$ & $2.5(1.5-3.0)$ \\
\hline \multicolumn{3}{|l|}{ Fracture type } \\
\hline Femoral neck & $17(57)$ & $14(47)$ \\
\hline Intertrochanteric & $12(40)$ & $13(43)$ \\
\hline Subtrochanteric & $1 \quad(3)$ & $3(10)$ \\
\hline Surgery performed & $n=29 \dagger$ & \\
\hline Open reduction and internal fixation & $17(59)$ & $16(53)$ \\
\hline Arthroplasty & $12(41)$ & $14(47)$ \\
\hline Anesthetic & $n=29 t$ & \\
\hline Neuroaxial & $25(86)$ & $24(80)$ \\
\hline General & $4(14)$ & $6(20)$ \\
\hline \multicolumn{3}{|c|}{$\begin{array}{l}\text { Note: } \mathrm{ADL}=\text { activities of daily living, } \mathrm{CAD}=\text { coronary artery disease, } \mathrm{CHF}=\text { congestive heart failure, } \\
\mathrm{COPD}=\text { chronic obstructive pulmonary disease, } \mathrm{DVT}=\text { deep vein thrombosis, } \mathrm{ED}=\text { emergency } \\
\text { department, } \mathrm{eGFR}=\text { estimated glomerular filtration rate, } \mathrm{PAD}=\text { peripheral arterial disease, } \\
\mathrm{Q}=\text { quartile, } \mathrm{SD}=\text { standard deviation, } \mathrm{TIA}=\text { transient ischemic attack, } \mathrm{UTI}=\text { urinary tract infection. } \\
\text { *Unless stated otherwise. } \\
\text { tOne patient declined surgery after enrolment. }\end{array}$} \\
\hline
\end{tabular}


ated the individual components of the main clinical outcome.

Individual secondary outcomes at 30 days after randomization included clinical outcomes (listed and defined in Appendix 2, available at www.cmaj .ca/lookup/suppl/doi:10.1503/cmaj.130901/-/DC1), delirium up to 7 days after randomization, time to first mobilization, length of stay (hospital, critical care and rehabilitation), new residence in a nursing home, and FIM and SF-36 scores..$^{27,28}$

\section{Statistical analyses}

We planned to enroll a convenience sample of 50 patients for this pilot trial. After amending the protocol to randomly assign patients after the diagnosis of hip fracture but before medical

Table 2: Timeline of diagnosis, medical clearance and surgery, by treatment group

\begin{tabular}{|c|c|c|}
\hline Variable & $\begin{array}{c}\text { Accelerated care } \\
\qquad n=30\end{array}$ & $\begin{array}{c}\text { Standard care } \\
\quad n=30\end{array}$ \\
\hline \multicolumn{3}{|c|}{ Medical clearance within $2 \mathrm{~h}$ of diagnosis, no. (\%) } \\
\hline Initial trial pathway & $6 / 6(100)$ & $4 / 5 \quad(80)$ \\
\hline Amended trial pathway & $17 / 24(71)$ & $2 / 25 \quad(8)$ \\
\hline Overall & $23 / 30(77)$ & $6 / 30(20)$ \\
\hline \multicolumn{3}{|c|}{ Diagnosis to medical clearance, $h$, median (IQR) } \\
\hline Initial trial pathway & $1.0(0.6-1.4)$ & $1.0(0.7-1.2)$ \\
\hline Amended trial pathway & $1.8(1.2-2.5)$ & $4.5(2.3-8.4)$ \\
\hline Overall & $1.5(1.1-2.0)$ & $3.4(1.0-7.9)$ \\
\hline \multicolumn{3}{|c|}{ Surgery within $6 \mathrm{~h}$ of diagnosis, no. (\%) } \\
\hline Initial trial pathway & $3 / 6 \quad(50)$ & $2 / 5 \quad(40)$ \\
\hline Amended trial pathway & $12 / 24(50)$ & $1 / 25 \quad(4)$ \\
\hline Overall & $15 / 30 \quad(50)$ & $3 / 30(10)$ \\
\hline \multicolumn{3}{|c|}{ Diagnosis to surgery, $h$, median (IQR) } \\
\hline Initial trial pathway & $6.1(4.0-7.3)$ & $21.1 \quad(5.7-25.7)$ \\
\hline Amended trial pathway & $6.0(4.2-12.8)$ & $24.5(13.0-29.5)$ \\
\hline Overall & $6.0(4.2-9.4)$ & $24.2(11.1-29.5)$ \\
\hline
\end{tabular}

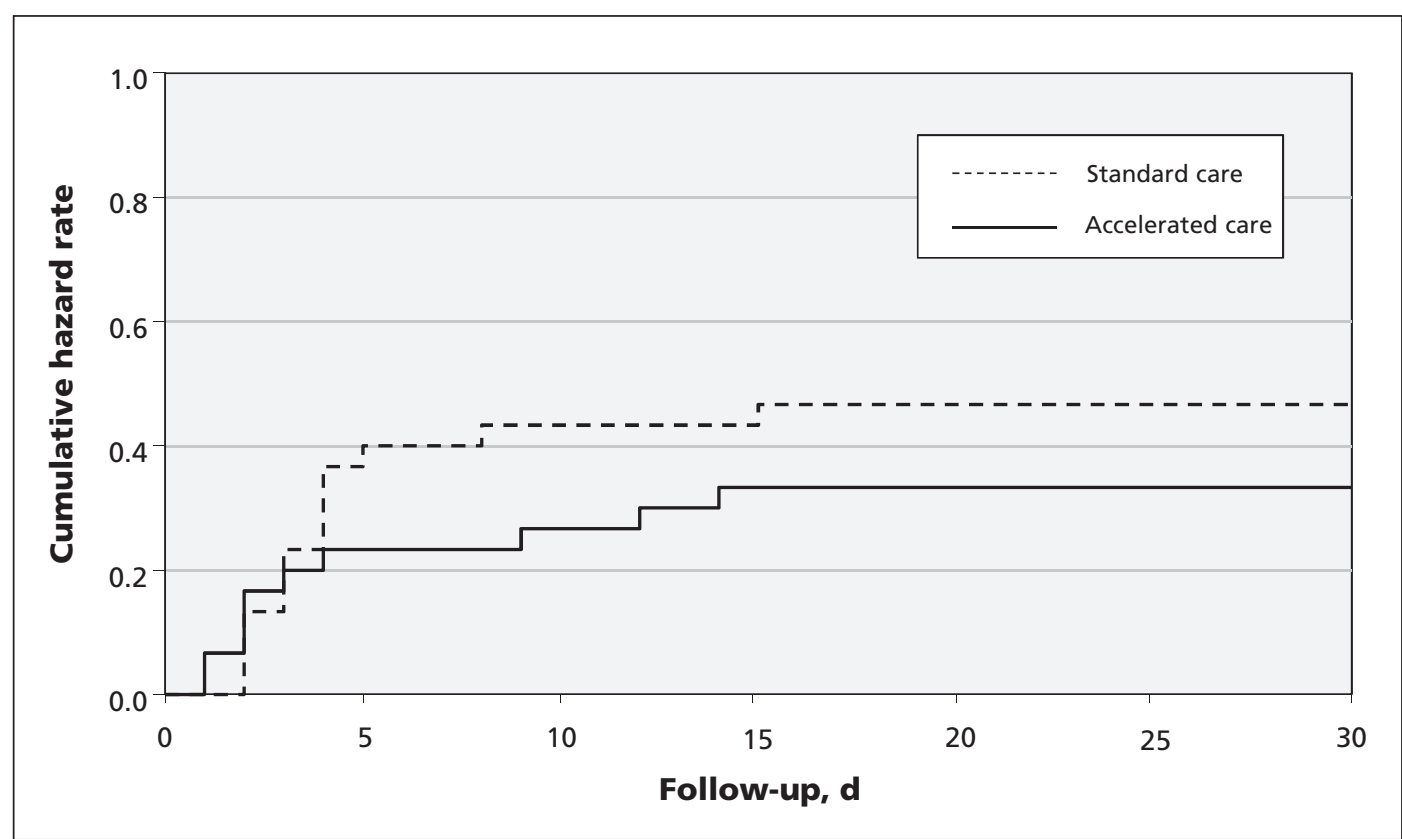

Figure 3: Kaplan-Meier curves of the composite endpoint of major perioperative complications (i.e., a composite of death, preoperative myocardial infarction, myocardial injury after noncardiac surgery, stroke, pulmonary embolism, pneumonia, and major or life-threatening bleeding). Note: $p=0.2$. 
clearance (i.e., after 11 patients were randomly assigned), we expanded the sample to 60 patients. All analyses included all randomly assigned patients, except for the analysis of time from randomization to surgery. In this analysis, we excluded 1 patient (from the accelerated care group) who decided not to undergo surgery. We analyzed patients in the treatment group to which they were originally allocated.

We determined the median time and interquartile range (IQR) from diagnosis to medical clearance, and from diagnosis to arrival in the operating room, by treatment group, among all patients and in the subgroup of patients randomly assigned in the initial and the amended trial pathways. We analyzed the time to the first occurrence of a major perioperative complication using a stratified Cox proportional hazards model. We applied a 2 -tailed $\alpha$ of 0.05 . We plotted the time to the first occurrence of a major perioperative complication for each treatment group using the Kaplan-Meier method. For secondary outcomes, we report mean and standard deviation (SD) or median and IQR, as appropriate, for continuous outcomes, and number and percent for categorical outcomes. To perform the statistical analyses, we used SAS version 9.2 for UNIX (SAS Institute).

\section{Results}

\section{Recruitment and completeness of follow-up}

Figure 2 shows the flow of patients through the trial. We randomly assigned 60 patients (including the 11 patients randomly assigned before the trial pathway was changed, Figure 1) at the 3 participating centres during a 14-month period starting in August 2011. Of patients eligible for inclusion, $80 \%$ consented and were randomly assigned (i.e., 30 to accelerated care and 30 to standard care). The mean recruitment rate was 2.2 patients per month per site. The mean rates of patient recruitment per month were 3.1, 1.3 and 2.1 for Canadian site 1, Canadian site 2 and the Indian site, respectively. During the trial, 3 patients were ineligible for inclusion because another patient had been included on the same day, and 342 patients were ineligible because their hip fracture was diagnosed outside of weekday, daytime working hours. All of the included patients completed the 30-day follow-up.

\section{Baseline demographics and characteristics}

Table 1 reports patient characteristics by treatment group. The mean age was $81(\mathrm{SD} \pm 9)$ years and most patients were female $(63 \%)$. Par- ticipants had a high burden of comorbidities (e.g., 68\% had hypertension, 20\% had coronary artery disease and $17 \%$ had dementia). The median time from injury to arrival in the emergency department was 1.9 hours in the accelerated care group and 1.6 hours in the standard care group. The median time between arrival in the emergency department and diagnosis of a hip fracture was 2.9 hours in the accelerated care group and 2.5 hours in the standard care group.

\section{Timeline of diagnosis, medical clearance and surgery}

Table 2 reports the timelines from diagnosis of hip fracture to medical clearance and surgery, by treatment group. The median time between diagnosis and medical clearance was 1.5 (IQR 1.1-2.0) hours in the accelerated care group and 3.4 (IQR, 1.0-7.9) hours in the standard care group ( $p=$ 0.01 ). The median time from diagnosis of hip fracture to surgery was 6.0 (IQR 4.2-9.4) hours in the accelerated care group and 24.2 (IQR 11.1-29.5) hours in the usual care group $(p<0.001)$. No patient had a condition likely to benefit from medical optimization before surgery (Appendix 1).

\section{Secondary outcomes}

A major perioperative complication within 30 days of randomization occurred in $9(30 \%)$ of

Table 3: Clinical outcome at 30 days, by treatment group

\begin{tabular}{|c|c|c|}
\hline \multirow[b]{2}{*}{ Outcome* } & \multicolumn{2}{|c|}{ No. (\%) of patients } \\
\hline & $\begin{array}{l}\text { Accelerated care } \\
\quad n=30\end{array}$ & $\begin{array}{l}\text { Standard care } \\
\quad n=30\end{array}$ \\
\hline Death & 1 (3) & $4(13)$ \\
\hline Vascular & 0 & $1 \quad(3)$ \\
\hline Nonvascular & 1 (3) & $3(10)$ \\
\hline Preoperative myocardial infarction & 0 & $1 \quad(3)$ \\
\hline $\begin{array}{l}\text { Myocardial injury after noncardiac } \\
\text { surgery }\end{array}$ & $4(13)$ & $7(23)$ \\
\hline Pulmonary embolism & 1 (3) & $1 \quad(3)$ \\
\hline Pneumonia & 1 (3) & $1 \quad(3)$ \\
\hline Major or life-threatening bleeding & $2(7)$ & $4(13)$ \\
\hline Congestive heart failure & 1 (3) & $4(13)$ \\
\hline $\begin{array}{l}\text { New clinically important atrial } \\
\text { fibrillation }\end{array}$ & $2(7)$ & $1 \quad(3)$ \\
\hline Deep vein thrombosis & 0 & $1 \quad(3)$ \\
\hline Sepsis & $2(7)$ & $1 \quad(3)$ \\
\hline $\begin{array}{l}\text { New acute renal failure treated } \\
\text { with dialysis }\end{array}$ & 0 & $1 \quad(3)$ \\
\hline $\begin{array}{l}\text { Delirium within } 7 \mathrm{~d} \text { after } \\
\text { randomization }\end{array}$ & $4(13)$ & $9(30)$ \\
\hline
\end{tabular}


the patients in the accelerated care group and 14 (47\%) of the patients in the standard care group (hazard ratio $0.60,95 \%$ CI $0.26-1.39, p=0.2$ ) (Figure 3). Tables 3 and 4 summarize the individual clinical and functional outcomes by treatment group. Appendix 3 (available at www.cmaj.ca /lookup/suppl/doi:10.1503/cmaj.130901/-/DC1) discusses the outcomes of the 6 patients who were receiving warfarin before randomization.

\section{Interpretation}

We enrolled patients with a hip fracture into an RCT of accelerated care compared with standard care. We surpassed our feasibility targets (i.e., we recruited 60 patients during a 14-month period, $80 \%$ of eligible patients were randomly assigned and $100 \%$ of patients completed the 30 day follow-up). Given that centres had a mean recruitment rate of 2.2 patients per month, we believe that a large adequately powered trial of 1000 patients is feasible; based on success to date, we project such recruitment during a period of 2.5-3 years at 15-20 international hospitals. Among patients randomly assigned to accelerated care, this pilot established the feasibility of accelerated medical clearance (i.e., the median time from diagnosis to medical clearance was $1.5 \mathrm{~h}$ ) and accelerated surgery (i.e., the median time from diagnosis to surgery was $6.0 \mathrm{~h}$ ).

The interval between diagnosis of hip fracture and surgery was reduced by more than 18 hours in the accelerated care group. This reduction was less marked with our initial protocol, which resulted in rapid medical clearance and earlier surgery in the group that received standard care. Furthermore, this pilot trial identified additional barriers to accelerated care such as treatment with an irreversible anticoagulant and access to PCC among patients taking warfarin. In a larger trial, avoidance of these barriers should increase the proportion of patients in the accelerated care group who have surgery within 6 hours, and further increase the difference in the time from diagnosis to surgery between the accelerated and standard care groups.

A major perioperative complication within 30 days of randomization occurred in almost half of the patients randomly assigned to standard care. This finding highlights the need to rigorously evaluate new approaches (e.g., accelerated care). Although this pilot trial was not powered for efficacy, the clinical results are encouraging.

Whereas observational data suggest that delayed surgery is associated with increased mortality and morbidity after a hip fracture, ${ }^{12,19,21,33-38}$ the individual studies applied varying time cut-offs (i.e., up to $72 \mathrm{~h}$ ) to define early surgery. Only one observational study involving 2056 patients explored the effect of surgical delay across 12-hour time frames from hospital admission. ${ }^{38}$ That study showed an adjusted dose response, which suggested that surgery within 12 hours of hospital admission had the largest effect and that this effect diminished across each additional 12-hour delay. The authors did not explore the effect of surgery at any period less than 12 hours from admission..$^{38}$ Although arbitrary, our target time for accelerated surgery was set at 6 hours after diagnosis of hip fracture. We believe that the shortest time possible will provide the greatest potential for benefit, as is the case in acute myocardial infarction and stroke. ${ }^{13,14}$

Table 4: Functional outcome at 30 days and length of stay, by treatment group

\begin{tabular}{|c|c|c|c|c|}
\hline \multirow[b]{2}{*}{ Variable } & \multicolumn{2}{|c|}{ Accelerated care } & \multicolumn{2}{|c|}{ Standard care } \\
\hline & $n$ & Median (IQR) & $n$ & Median (IQR) \\
\hline FIM score & 29 & $62(33-86)$ & 25 & $53(29-85)$ \\
\hline SF-36 physical score & 22 & $30.6(25.2-36.5)$ & 13 & $29.5(25.9-33.2)$ \\
\hline SF-36 mental score & 22 & $56.4(40.9-62.9)$ & 13 & $58.8(43.3-64.0)$ \\
\hline $\begin{array}{l}\text { Time from randomization to first } \\
\text { mobilization, } d\end{array}$ & 25 & $3(2-6)$ & 26 & $4(3-5)$ \\
\hline Length of stay in critical care, $d$ & 5 & $3(2-4)$ & 7 & $3(1-6)$ \\
\hline Length of stay in hospital, d & 30 & $9.5(8-17)$ & 30 & $12(7-17)$ \\
\hline Length of stay in rehabilitation, $d$ & 16 & $21(17.5-23)$ & 11 & $15(13-22)$ \\
\hline $\begin{array}{l}\text { Combined length of stay in hospital and } \\
\text { rehabilitation, } d\end{array}$ & 30 & $30(9-30)$ & 30 & $22(7-30)$ \\
\hline
\end{tabular}




\section{Strengths and limitations}

Strengths of this pilot trial include the multicentre conduct at 3 sites in 2 countries. We developed the protocol through interdisciplinary collaboration among hospital administrators, emergency department physicians, internists, anesthesiologists and surgeons, which resulted in the successful conduct of the trial. The outcome adjudicators were unaware of treatment allocation, and during the first 7 days all patients had daily assessments for delirium (through a validated tool) and prognostically relevant perioperative myocardial injury (through troponin measurements). ${ }^{39} \mathrm{We}$ achieved complete follow-up at 30 days for all randomly assigned patients, and we reported the trial as per the CONSORT (Consolidated Standards of Reporting Trials) recommendations. ${ }^{40}$ Finally, this pilot trial identified design issues that we were able to overcome through protocol amendments.

Our trial also had limitations. Although the individuals who randomly assigned patients were instructed not to inform the data collectors of treatment allocation, data collectors may have deduced treatment allocation through documentation about the time of surgery. The impact of this possibility may have been mitigated because some patients assigned to accelerated care had surgery delayed and some patients assigned to standard care underwent surgery within 6 hours of receiving their diagnosis.

\section{Conclusion}

This pilot trial shows the feasibility of a trial comparing accelerated and standard care among patients with a hip fracture. The results provide encouraging evidence that accelerated surgery may substantially improve outcomes in these patients. Based on what we learned in this pilot, we have now designed a full trial that incorporates our amended treatment pathway (i.e., random allocation of patients before medical clearance), ensures access to PCC for patients taking warfarin and excludes patients taking an irreversible anticoagulant. We plan to start this adequately powered trial early in 2014 to determine whether accelerated surgical care prevents major perioperative complications. Researchers interested in joining the trial should contact the authors.

\section{References}

1. Brauer CA, Coca-Perraillon M, Cutler DM, et al. Incidence and mortality of hip fractures in the United States. JAMA 2009;302: 1573-9.

2. Prevention of pulmonary embolism and deep vein thrombosis with low dose aspirin: Pulmonary Embolism Prevention (PEP) trial. Lancet 2000;355:1295-302.

3. LeBlanc ES, Hillier TA, Pedula KL, et al. Hip fracture and increased short-term but not long-term mortality in healthy older women. Arch Intern Med 2011;171:1831-7.

4. Nurmi I, Narinen A, Lüthje P, et al. Functional outcome and sur- vival after hip fracture in elderly: a prospective study of 106 consecutive patients. J Orthop Traumatol 2004;5:7-14.

5. Beloosesky Y, Hendel D, Weiss A, et al. Cytokines and C-reactive protein production in hip-fracture-operated elderly patients. J Gerontol A Biol Sci Med Sci 2007;62:420-6.

6. Chuang D, Power SE, Dunbar PR, et al. Central nervous system interleukin-8 production following neck of femur fracture. ANZ J Surg 2005;75:813-6.

7. Desborough JP. The stress response to trauma and surgery. $\mathrm{Br} J$ Anaesth 2000;85:109-17.

8. Miller RR, Shardell MD, Hicks GE, et al. Association between interleukin- 6 and lower extremity function after hip fracture the role of muscle mass and strength. J Am Geriatr Soc 2008;56: 1050-6.

9. Onuoha GN, Alpar EK. Elevation of plasma CGRP and SP levels in orthopedic patients with fracture neck of femur. Neuropeptides 2000;34:116-20

10. Svensén CH. Vascular endothelial growth factor (VEGF) in plasma increases after hip surgery. J Clin Anesth 2004;16:435-9.

11. Tsangari H, Findlay DM, Kuliwaba JS, et al. Increased expression of IL-6 and RANK mRNA in human trabecular bone from fragility fracture of the femoral neck. Bone 2004;35:334-42.

12. Simunovic N, Devereaux PJ, Sprague S, et al. Effect of early surgery after hip fracture on mortality and complications: systematic review and meta-analysis. CMAJ 2010;182:1609-16.

13. Hacke W, Donnan G, Fieschi C, et al. Association of outcome with early stroke treatment: pooled analysis of ATLANTIS, ECASS, and NINDS rt-PA stroke trials. Lancet 2004;363:768-74.

14. Ryan TJ, Anderson JL, Antman EM, et al. ACC/AHA guidelines for the management of patients with acute myocardial infarction: executive summary. A report of the American College of Cardiology/American Heart Association Task Force on Practice Guidelines (Committee on Management of Acute Myocardial Infarction). Circulation 1996;94:2341-50.

15. Ho V, Hamilton BH, Roos LL. Multiple approaches to assessing the effects of delays for hip fracture patients in the United States and Canada. Health Serv Res 2000;34:1499-518.

16. Adie S, Harris IA, Thorn L, et al. Non-emergency management of hip fractures in older patients. J Orthop Surg (Hong Kong) 2009; 17:301-4.

17. Moran CG, Wenn RT, Sikand M, et al. Early mortality after hip fracture: Is delay before surgery important? J Bone Joint Surg Am 2005;87:483-9.

18. White SM, Griffiths R, Holloway J, et al. Anaesthesia for proximal femoral fracture in the UK: first report from the NHS Hip Fracture Anaesthesia Network. Anaesthesia 2010;65:243-8.

19. Sund R, Liski A. Quality effects of operative delay on mortality in hip fracture treatment. Qual Saf Health Care 2005;14:371-7.

20. Orosz GM, Magaziner J, Hannan EL, et al. Association of timing of surgery for hip fracture and patient outcomes. JAMA 2004;291:1738-43.

21. McGuire KJ, Bernstein J, Polsky D, et al. The 2004 Marshall Urist award: delays until surgery after hip fracture increases mortality. Clin Orthop Relat Res 2004;294-301.

22. Berger A, Stauffer JC, Radovanovic D, et al. Comparison of inhospital mortality for acute myocardial infarction in Switzerland with admission during routine duty hours versus admission during out of hours (insight into the AMIS plus registry). Am J Cardiol 2008;101:422-7.

23. Roche JJ, Wenn RT, Sahota O, et al. Effect of comorbidities and postoperative complications on mortality after hip fracture in elderly people: prospective observational cohort study. BMJ 2005;331:1374.

24. Inouye SK, van Dyck CH, Alessi CA, et al. Clarifying confusion: the confusion assessment method. A new method for detection of delirium. Ann Intern Med 1990;113:941-8.

25. Wei LA, Fearing MA, Sternberg EJ, et al. The Confusion Assessment Method: a systematic review of current usage. J Am Geriatr Soc 2008;56:823-30.

26. Stineman MG, Shea JA, Jette A, et al. The Functional Independence Measure: tests of scaling assumptions, structure, and reliability across 20 diverse impairment categories. Arch Phys Med Rehabil 1996;77:1101-8

27. Latham NK, Mehta V, Nguyen AM, et al. Performance-based or self-report measures of physical function: Which should be used in clinical trials of hip fracture patients? Arch Phys Med Rehabil 2008;89:2146-55.

28. Mangione KK, Craik RL, Palombaro KM, et al. Home-based legstrengthening exercise improves function 1 year after hip fracture: a randomized controlled study. J Am Geriatr Soc 2010;58:1911-7.

29. Roy L, Laflamme GY, Carrier M, et al. A randomised clinical trial comparing minimally invasive surgery to conventional approach for endoprosthesis in elderly patients with hip fractures. Injury 2010;41:365-9. 
30. McGrory BJ, Shinar AA, Freiberg AA, et al. Enhancement of the value of hip questionnaires by telephone follow-up evaluation. J Arthroplasty 1997;12:340-3.

31. Petrella RJ, Overend T, Chesworth B. FIM after hip fracture: Is telephone administration valid and sensitive to change? Am J Phys Med Rehabil 2002;81:639-44.

32. Botto F, Alonso-Coello P, Chan MTV, et al., and the VISION Investigators. Myocardial injury after noncardiac surgery: a large international prospective cohort study establishing diagnostic criteria, characteristics, predictors, and 30-day outcomes. Anesthesiology. In press.

33. Bottle A, Aylin P. Mortality associated with delay in operation after hip fracture: observational study. BMJ 2006:332:947-51.

34. Gdalevich M, Cohen D, Yosef D, et al. Morbidity and mortality after hip fracture: the impact of operative delay. Arch Orthop Trauma Surg 2004;124:334-40.

35. Novack V, Jotkowitz A, Etzion O, et al. Does delay in surgery after hip fracture lead to worse outcomes? A multicenter survey. Int J Oual Health Care 2007;19:170-6.

36. Radcliff TA, Henderson WG, Stoner TJ, et al. Patient risk factors, operative care, and outcomes among older communitydwelling male veterans with hip fracture. J Bone Joint Surg Am 2008;90:34-42.

37. Weller I, Wai EK, Jaglal S, et al. The effect of hospital type and surgical delay on mortality after surgery for hip fracture. J Bone Joint Surg Br 2005;87:361-6.

38. Uzoigwe CE, Burnand HG, Cheesman CL, et al. Early and ultraearly surgery in hip fracture patients improves survival. Injury 2013;44:726-9.

39. Devereaux PJ, Chan MT, Alonso-Coello P, et al. Association between postoperative troponin levels and 30-day mortality among patients undergoing noncardiac surgery. JAMA 2012;307: 2295-304.

40. Moher D, Hopewell S, Schulz KF, et al. CONSORT 2010 explanation and elaboration: updated guidelines for reporting parallel group randomised trials. BMJ 2010;340:c869.

The Hip Fracture Accelerated Surgical Treatment and Care Track (HIP ATTACK) Investigators: Giovanna Lurati Buse MD MSc, Mohit Bhandari MD PhD, Parag Sancheti MD MCh, Steve Rocha MD, Mitchell Winemaker MD, Anthony Adili PEng MD, Justin de Beer MBChB, Maria Tiboni MD, John D.D. Neary MD, Valerie Dunlop BSc, Leslie Gauthier MSc, Ameen Patel MB, Andrea Robinson BSc, Reitze N. Rodseth MBChB PhD, Rick Kolesar MD, Janet Farrell MD, Mark Crowther MD MSc, Vikas Tandon MD, Patrick Magloire MD, Hisham Dokainish MD, Philip Joseph MD, Charles W. Tomlinson MD PhD, Omid Salehian MD MSc, Debbie Hastings MD, Dereck L. Hunt MD MSc, Harriette Van Spall MD MPH, Tammy L. Cosman RN(EC) PhD, Diane L. Simpson MD MA, David Cowan MD, Gordon Guyatt MD MSc, Kim Alvarado RN PhD, W.K. (Bill) Evans MD, Ryszard Mizera MD, John Eikelboom MBBS MSc, Deborah Cook MD MSc, Mark Loeb MD MSc, Jennie Johnstone MD, Clive Kearon MB PhD, Daniel I. Sessler MD, Thomas VanHelder MD PhD, Purnima RaoMelacini MSc, Andrew Worster MD MSc, Atul Patil MD, Richard McLean MD, Anne-Marie Macdonald RN, Rick Badzioch MBA, P.J. Devereaux MD PhD

Affiliations: Population Health Research Institute (Dunlop, Robinson, Rodseth, Van Spall, Rao-Melacini, Devereaux), Hamilton, Ont.; Department of Anesthesiology (Buse), University Hospital of Basel, Basel, Switzerland; Department of Surgery (Bhandari, Winemaker, Adili, de Beer), McMaster University, Hamilton, Ont.; Sancheti Institute for Orthopaedics and Rehabilitation (Sancheti), Pune, India;
Department of Orthopaedics (Rocha, Patil), Sancheti Institute for Orthopaedics and Rehabilitation, Pune, India; Department of Medicine (Tiboni, Neary, Patel, Robinson, Crowther, Tandon, Magloire, Dokainish, Joseph, Tomlinson, Salehian, Hastings, Hunt, Van Spall, Cowan, Guyatt, Mizera, Eikelboom, Cook, Kearon, Rao-Melacini, Devereaux), McMaster University, Hamilton, Ont.; Hamilton Health Sciences (Gauthier, Cosman, Alvarado, Evans), Hamilton, Ont.; Department of Outcomes Research (Rodseth, Sessler), Cleveland Clinic, Cleveland, Ohio; Department of Anaesthetics (Rodseth), Inkosi Albert Luthuli Central Hospital, Nelson R. Mandela School of Medicine, University of KwaZulu-Natal, Durban, South Africa; Department of Anesthesia (Kolesar, Farrell, VanHelder), McMaster University, Hamilton, Ont.; Department of Anesthesia (Farrell, McLean), St. Joseph's Healthcare Hamilton, Hamilton, Ont.; Division of Emergency Medicine (Simpson, Worster), McMaster University, Hamilton, Ont.; Department of Family Medicine (Simpson), McMaster University, Hamilton, Ont.; Department of Clinical Epidemiology and Biostatistics (Guyatt, Cook, Loeb, Johnstone, Kearon, Devereaux), McMaster University, Hamilton, Ont.; Department of Oncology (Evans), McMaster University, Hamilton, Ont.; Department of Pathology and Molecular Medicine (Loeb), McMaster University, Hamilton, Ont.; St. Joseph's Healthcare Hamilton (Macdonald, Badzioch), Hamilton, Ont.

Contributors: P.J. Devereaux, Giovanna Lurati Buse, Mohit Bhandari, Mitchell Winemaker, Anthony Adili, Justin de Beer, Maria Tiboni, John Neary, Leslie Gauthier, Ameen Patel, Reitze Rodseth, Rick Kolesar, Janet Farrell, Mark Crowther, Vikas Tandon, Patrick Magloire, Hisham Dokainish, Dereck Hunt, Tammy Cosman, Diane Simpson, David Cowan, Gordon Guyatt, Kim Alvarado, W.K. (Bill) Evans, Ryszard Mizera, John Eikelboom, Deborah Cook, Mark Loeb, Jennie Johnstone, Clive Kearon, Daniel Sessler, Thomas VanHelder, Andrew Worster, Richard McLean, Anne-Marie MacDonald and Rich Badzioch contributed substantially to the conception and design of this trial. Giovanna Lurati Buse, P.J. Devereaux, Mohit Bhandari, Parag Sancheti, Steve Rocha, Mitchell Winemaker, Anthony Adili, Justin de Beer, Maria Tiboni, John Neary, Valerie Dunlop, Ameen Patel, Andrea Robinson, Reitze Rodseth, Vikas Tandon, Patrick Magloire, Hisham Dokainish, Philip Joseph, Charles Tomlinson, Omid Salehian, Debbie Hastings, Dereck Hunt, Harriette Van Spall, Tammy Cosman, Ryszard Mizera, Thomas VanHelder, Atul Patil and Diane Simpson contributed to the acquisition of data. Purnima Rao-Melacini, Giovanna Lurati Buse, P.J. Devereaux, Mohit Bhandari, Daniel Sessler and Reitze Rodseth contributed to the analysis and interpretation of data. Giovanna Lurati Buse and P.J. Devereaux drafted the article, which all of the authors revised. All of the authors approved the final version submitted for publication.

Funding: This trial was funded through grants from Academic Health Science Centres Alternative Funding Plan Innovation Fund of Ontario and Octapharma Canada. The trial funders had no role in the design of the study, the collection, analysis or interpretation of data, the writing of the report, or the decision to submit the article for publication.

Acknowledgement: This trial was coordinated by the Population Health Research Institute, at the Hamilton Health Sciences, McMaster University, Hamilton, Ont. 